\title{
Alzheimer's disease as a metabolic disorder
}

\author{
George S. Bloom ${ }^{1,2,3, *}$ and Andrés Norambuena ${ }^{1}$ \\ ${ }^{1}$ Department of Biology, University of Virginia, Charlottesville, Virginia, USA \\ 2 Department of Cell Biology, University of Virginia, Charlottesville, Virginia, USA \\ ${ }^{3}$ Department of Neuroscience, University of Virginia, Charlottesville, Virginia, USA
}

Received 7 August 2018 - Accepted 9 August 2018

\begin{abstract}
Alzheimer's disease (AD) is defined by memory loss and cognitive impairment, along with the accumulation in brain of two types of abnormal structures, extracellular amyloid plaques and intraneuronal neurofibrillary tangles. Both plaques and tangles are composed predominantly of poorly soluble filaments that respectively assemble from amyloid- $\beta(\mathrm{A} \beta)$ peptides and the neuron-specific, microtubule-associated protein, tau. It is now widely acknowledged that soluble oligomers of $A \beta$ and tau, the building blocks of plaques and tangles, are principal drivers of $\mathrm{AD}$ pathogenesis by acting coordinately to impair and destroy synapses, and kill neurons. The behavioral features of $\mathrm{AD}$ are a direct consequence of these attacks on synapses and neuronal viability, which in turn reflect a reduced capacity of AD neurons to utilize energy sources needed to maintain neuronal function and vitality. In other words, AD neurons are starving, even when they may be surrounded by abundant nutrients. Here, we review some of the evidence for the metabolic deficiencies of neurons in $\mathrm{AD}$ and how they impact neuronal health.
\end{abstract}

Keywords: amyloid- $\beta$ / tau / mTOR / insulin / mitochondria

Résumé - La maladie d'Alzheimer en tant que trouble métabolique. La maladie d'Alzheimer (MA) est définie par la perte de mémoire et la déficience cognitive avec l'accumulation dans le cerveau de deux types de structures anormales, des plaques amyloïdes extracellulaires et des enchevêtrements neurofibrillaires intraneuronaux. Les plaques et les enchevêtrements sont composés principalement de filaments peu solubles qui s'assemblent respectivement à partir de peptides amyloïde- $\beta(A \beta)$ et de la protéine tau spécifique aux neurones, associée aux microtubules. Il est maintenant largement reconnu que les oligomères solubles d'A $\beta$ et de tau, éléments constructifs des plaques et des enchevêtrements neurofibrillaires, sont les principaux moteurs de la pathogenèse de la maladie d'Alzheimer en agissant de manière coordonnée pour altérer et détruire les synapses et tuer les neurones. Les caractéristiques comportementales de la maladie d'Alzheimer sont une conséquence directe de ces attaques sur les synapses et la viabilité neuronale, qui à leur tour reflètent une capacité réduite des neurones, lors de la maladie, à utiliser les sources d'énergie nécessaire pour maintenir la fonction neuronale et la vitalité. En d'autres termes, les neurones de la maladie d'Alzheimer sont affamés, même lorsqu'ils sont entourés de nutriments abondants. Dans cet article, nous passons en revue certaines des preuves des déficiences métaboliques des neurones dans la maladie d'Alzheimer et comment ils affectent la santé neuronale.

Mots clés : amyloïde- $\beta$ / tau / mTOR / insuline / mitochondries

\section{Introduction}

The well known behavioral symptoms of Alzheimer's disease (AD) are caused by two phenomena: the compromised function and eventual loss of synapses on neurons that mediate memory and cognition, and by the death of those neurons.

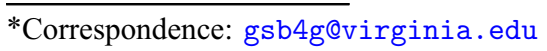

A detailed understanding of the molecular mechanisms that cause neuronal decline in $\mathrm{AD}$ has been frustratingly slow to develop. Gaining such an understanding, however, is bound to enhance efforts to devise effective means of preventing $\mathrm{AD}$ onset or significantly slowing its progression.

While many neurodegenerative disorders are characterized by memory loss and cognitive impairment, $\mathrm{AD}$ is distinguished from all others by the accumulation in brain of extracellular 
amyloid plaques and intraneuronal neurofibrillary tangles. The most notable ultrastructural feature of plaques and tangles is tightly packed filaments with diameters in the $\sim 10 \mathrm{~nm}$ range and variable lengths. At the biophysical and biochemical levels, both filament types are poorly soluble, but they are composed of distinct building blocks. Whereas the filaments in plaques are made from amyloid- $\beta$ (A $\beta)$ peptides, which are derived by proteolysis from the widely expressed, single pass transmembrane protein, APP (Kang et al., 1987; Masters et al., 1985), the filaments in tangles assemble from the neuronspecific protein, tau (Grundke-Iqbal et al., 1986; Kondo et al., 1988; Kosik et al., 1988), which is normally found primarily in association with axonal microtubules (Binder et al., 1985; Weingarten et al., 1975).

Because of how visually conspicuous plaques and tangles are in $\mathrm{AD}$ brain, it is not surprising that $\mathrm{AD}$ research aimed at controlling the disease has been dominated by efforts to block plaques and tangles from forming and eliminate them once they have formed, in the hope that doing so would prevent, reverse or alleviate symptoms. The past 15 years, however, have witnessed a growing realization that the cellular and molecular processes leading to neuronal decline in $\mathrm{AD}$ begin decades before symptoms are evident (Villemagne et al., 2013), and that those processes are driven by soluble, misfolded forms of $A \beta$ and tau independently of their respective incorporation into plaques and tangles (Bloom, 2014). Particular progress has been made toward understanding how $A \beta$ oligomers ( $A \beta O s$ ) and soluble forms of tau drive synapse loss and neuronal cell cycle re-entry (CCR), the latter of which may lead to the bulk of neuron death in AD (Arendt et al., 2010; Ittner et al., 2010; Seward et al., 2013; Varvel et al., 2008). Emerging from that body of work and related approaches is the realization that AD neurons are chronically undernourished because they cannot effectively use abundant nutrients and trophic factors that surround them.

\section{The signaling network for neuronal CCR in $A D$}

Although the degree to which new neurons are produced from neuronal precursor cells in the juvenile and adult mammalian brain has stimulated much debate (Pilz et al., 2018; Sorrells et al., 2018), it is widely agreed that differentiated neurons are permanently post-mitotic. More than 20 years ago, however, evidence for extensive neuronal CCR in AD brain began to accumulate (McShea et al., 1999; Nagy et al., 1997; Yang et al., 2003). Subsequent studies indicated that CCR neurons do not divide, but instead eventually die and may account for the lion's share of neuron death in AD (Arendt et al., 2010). Further observations of high neuronal CCR levels have been made in numerous transgenic mouse models of AD (Li et al., 2011; Norambuena et al., 2017; Seward et al., 2013; Varvel et al., 2008).

The first clues to the mechanism for neuronal CCR followed the observation that oligomers, but neither monomeric nor fibrillar forms of $A \beta$ can drive primary cultured rodent neurons to exit the quiescent G0 state, and express various molecular markers indicative of the $\mathrm{G} 1$ and $\mathrm{S}$ phases of the cell cycle (Varvel et al., 2008). This AßOinduced neuronal CCR was found to be blocked by inhibitors of mechanistic target of rapamycin (mTOR) signaling, implicating mTOR as a key regulatory factor (Seward et al., 2013; Varvel et al., 2008).

mTOR is a serine-threonine-directed protein kinase present in two multi-protein complexes, mTORC1 and mTORC2. Together, the mTOR complexes respond to extracellular nutrients and trophic factors, such as amino acids, glucose and insulin, to regulate fundamental processes like cell growth, division and survival, and autophagy and mRNA translation, among several others (Zoncu et al., 2011). A principal site of action for mTORC1 is the lysosomal surface, where its activation leads to inhibition of autophagy and promotion of translation (Zoncu et al., 2011).

We recently reported that $\mathrm{A} \beta \mathrm{O}$ s and tau work together to cause dysregulation of normal mTORC1 signaling as a requisite step for neuronal CCR (Norambuena et al., 2017). $\mathrm{A} \beta \mathrm{O}$ s were found to activate $\mathrm{mTORC} 1$ as effectively as amino acids or insulin, but that activation was predominantly at the plasma membrane, at the expense of lysosomal mTORC1. A contributing factor to this mislocalized mTORC1 activation may be A $\beta O$-induced, partial loss of mTORC1 from the lysosomal surface. mTORC1-dependent tau phosphorylation at S262 is essential for CCR, and neither selective activation of plasma membrane mTORC1 nor neuronal CCR were observed in A $\mathrm{BO}$-treated tau knockout neurons despite the finding that A $\beta O$ s simulate mTORC1 in tau knockout neurons as effectively as in wild type neurons. A $\beta O$ s therefore induce a toxic feedback loop involving tau and mTORC1: tau must be phosphorylated at S262 by mTORC1, or more likely by S6 kinase, which is phosphoactivated by mTORC1, to sustain the mislocalized mTORC1 activation at the plasma membrane that is required for CCR (Norambuena et al., 2017).

Remarkably, the ability of A $\beta O$ s to induce CCR in cultured neurons can be blocked by insulin, which activates lysosomal mTORC1, or by reducing expression of the lysosomeassociated mTORC1 inhibitors, TSC2 or Nprl3 (Norambuena et al., 2017). These observations indicate that while A $\beta O-$ induced, tau-dependent activation of plasma membrane mTORC1 is necessary for CCR, that effect can be overridden by simultaneous activation of lysosomal mTORC1. They also suggest that boosting insulin signaling in the $\mathrm{AD}$ brain might have therapeutic value, and indeed, intranasal insulin delivery is being tested in clinical trials (Claxton et al., 2015; Craft et al., 2017). If intranasal insulin does not prove to be as effective as hoped, it may be because the AD brain has reduced responsiveness to insulin (Steen et al., 2005), a condition initially caused by $\mathrm{A} \beta \mathrm{O}$-induced sequestration of insulin receptors into the neuronal cytoplasm (Bomfim et al., 2012), and later by a dramatic drop in the levels of insulin receptor protein and mRNA (Steen et al., 2005). The well-known reduction of glucose uptake in $\mathrm{AD}$ brain is likely a consequence of this reduced insulin signaling and occurs independently of systemic type 2 diabetes, which prompted the idea that $\mathrm{AD}$ should be classified as brain-specific, or type 3 diabetes (de la Monte, 2014). Regardless of whether or not type 3 diabetes is a justifiable descriptor of $\mathrm{AD}$, the diminished capacity of the AD brain to respond to insulin and utilize glucose underscores how AD neurons may act as starved cells even when nutrients and trophic factors are in ample supply.

In the context of neuronal CCR, $A \beta O$ s act as two-edged swords. They are responsible for initiating the insulin 
resistance that characterizes $\mathrm{AD}$ neurons. This insulin resistance then unleashes the further toxic potential of $\mathrm{A} \beta \mathrm{Os}$ to drive post-mitotic neurons back into the cell cycle, which eventually leads to their death.

\section{Mitochondrial dysfunction in AD: mTORC1 gone awry again}

Mitochondria are the power plants that convert extracellular nutrients into intracellular fuel in the form of ATP. While the reduced ability of $\mathrm{AD}$ neurons to utilize extracellular nutrients imposes obvious limits to the activity of their mitochondria, we recently discovered a separate mechanism by which mTORC 1 dysregulation by $\mathrm{A} \beta \mathrm{O}$ and tau causes mitochondrial dysfunction (Norambuena et al., 2018). This discovery was based on prior knowledge that the coenzymes, $\mathrm{NADH}$ and NADPH, exhibit weak intrinsic fluorescence whose lifetimes increase several-fold when the coenzymes are bound to enzyme partners (Blacker et al., 2014). We first demonstrated that the vast majority of $\mathrm{NAD}(\mathrm{P}) \mathrm{H}$ fluorescence co-localizes with mitochondria, and that $\sim 2 / 3$ of the intrinsic mitochondrial fluorescence in neuronal perikarya is due to $\mathrm{NADH}$, which is involved in glycolysis and the TCA cycle. We then used 2-photon fluorescence lifetime microscopy to measure $\mathrm{NAD}(\mathrm{P}) \mathrm{H}$ fluorescence lifetime as an indicator of mitochondrial activity.

Using that approach, we found that activation of lysosomal mTORC1 by insulin or amino acids stimulates mitochondrial activity. This nutrient-induced mitochondrial activity (NiMA) was found to depend on activation of lysosomal mTORC1, and could be blocked by $\mathrm{A} \beta \mathrm{O}$ s in a tau-dependent manner. The ability of A $\beta O$ s to inhibit NiMA reflects their tau-dependent stimulation of plasma membrane mTORC1 at the expense of lysosomal, mTORC1, which as described earlier is also required for neuronal CCR. Furthermore, mitochondrial DNA replication, as monitored by EdU uptake, was dramatically reduced by insulin or amino acids, but not when $\mathrm{A} \beta \mathrm{O}$ s were present. Taken together, these results indicate that lysosomal mTORC 1 couples nutrient availability to mitochondrial activity, and links mitochondrial dysfunction to $\mathrm{AD}$ by a mechanism dependent on soluble $\mathrm{A} \beta \mathrm{O}$ s and tau independently of their integration into plaques and tangles (Norambuena et al., 2018).

\section{Conclusions}

The AD brain is characterized by reduced insulin sensitivity (Steen et al., 2005) and nutrient (fluorodeoxyglucose) uptake (Mosconi, 2013). A key question that had remained unanswered is whether this reduced metabolic activity of $\mathrm{AD}$ brain represents a downstream effect of neuronal deterioration or a prime cause of that deterioration. It now seems clear that impaired metabolic activity lies high upstream in the chain of events that leads to the functional decline and death of neurons in AD. The ability of A $\beta O$ s to cause acute sequestration into the cytoplasm of insulin receptors (Bomfim et al., 2012) and eventually reduce receptor levels dramatically (Steen et al., 2005) makes it possible for $\mathrm{A} \beta O$ s to drive neuronal $\mathrm{CCR}$, and by extension neuron death (Norambuena et al., 2017). A second, and equally adverse consequence of neuronal exposure to $\mathrm{A} \beta \mathrm{O}$ s is inhibition of
NiMA. AD neurons are thus surrounded by nutrients and trophic factors that they cannot effectively or efficiently use, and it is therefore no wonder that they spiral into functional and viability decline.

Acknowledgments. George Bloom's and Andrés Norambuena's work on $\mathrm{AD}$ has been generously supported by the following sources: The Owens Family foundation (GSB), NIH/NIA grant RF1 AG051085 (GSB), The Alzheimer's Association Zenith Fellowship number ZEN-16-363266 and grant number 4079 (GSB), The Cure Alzheimer's Fund (GSB), The Alzheimer's and Related Diseases Research Award Fund grant 17-5 (AN), Webb and Tate Wilson (GSB), The Virginia Chapter of the Lady's Auxiliary of the Fraternal Order of Eagles (GSB), and the University of Virginia President's Fund for Excellence (GSB).

\section{References}

Arendt T, Bruckner MK, Mosch B, Losche A. 2010. Selective cell death of hyperploid neurons in Alzheimer's disease. Am J Pathol 177: $15-20$.

Binder LI, Frankfurter A, Rebhun LI. 1985. The distribution of tau in the nervous system. J Cell Biol 101: 1371-1378.

Blacker TS, Mann ZF, Gale JE, et al. 2014. Separating NADH and NADPH fluorescence in live cells and tissues using FLIM. Nature Commun. 5: article number 3936.

Bloom GS. 2014. Amyloid-beta and Tau: the Trigger and Bullet in alzheimer disease pathogenesis. JAMA Neurol 71: 505-508.

Bomfim TR, Forny-Germano L, Sathler LB, et al. 2012. An antidiabetes agent protects the mouse brain from defective insulin signaling caused by Alzheimer's disease-associated Abeta oligomers. J Clin Invest 122: 1339-1353.

Claxton A, Baker LD, Hanson A, et al. 2015. Long-acting intranasal insulin detemir improves cognition for adults with mild cognitive impairment or early-stage Alzheimer's disease dementia. $J$ Alzheimer's Dis 44: 897-906.

Craft S, Claxton A, Baker LD, et al. 2017. Effects of regular and longacting insulin on cognition and Alzheimer's disease biomarkers: a pilot clinical trial. J Alzheimer's Dis 57: 1325-1334.

de la Monte SM. 2014. Type 3 diabetes is sporadic Alzheimer's disease: Mini-review. Eur Neuropsychopharm 24: 1954-1960.

Grundke-Iqbal I, Iqbal K, Tung YC, Quinlan M, Wisniewski HM, Binder LI. 1986. Abnormal phosphorylation of the microtubuleassociated protein tau (tau) in Alzheimer cytoskeletal pathology. Proc Natl Acad Sci U S A 83: 4913-4917.

Ittner LM, Ke YD, Delerue F, et al. 2010. Dendritic function of tau mediates amyloid-beta toxicity in Alzheimer's disease mouse models. Cell 142: 387-397.

Kang J, Lemaire HG, Unterbeck A, et al. 1987. The precursor of Alzheimer's disease amyloid A4 protein resembles a cell-surface receptor. Nature 325: 733-736.

Kondo J, Honda T, Mori H, et al. 1988. The carboxyl third of tau is tightly bound to paired helical filaments. Neuron 1: 827-834.

Kosik KS, Orecchio LD, Binder L, Trojanowski JQ, Lee VMY, Lee G. 1988. Epitopes that span the tau molecule are shared with paired helical filaments. Neuron 1: 817-825.

Li L, Cheung T, Chen J, Herrup K. 2011. A comparative study of five mouse models of Alzheimer's disease: cell cycle events reveal new insights into neurons at risk for death. Int J Alzheimer's Dis 2011: article ID 171464.

Masters CL, Simms G, Weinman NA, Multhaup G, McDonald BL, Beyreuther K. 1985. Amyloid plaque core protein in Alzheimer 
disease and Down syndrome. Proc Natl Acad Sci U S A 82: 4245 4249.

McShea A, Wahl AF, Smith MA. 1999. Re-entry into the cell cycle: a mechanism for neurodegeneration in Alzheimer disease. Med Hypotheses 52: 525-527.

Mosconi L. 2013. Glucose metabolism in normal aging and Alzheimer's disease: Methodological and physiological considerations for PET studies. Clin Transl Imaging 1: 217-233

Nagy Z, Esiri MM, Cato AM, Smith AD. 1997. Cell cycle markers in the hippocampus in Alzheimer's disease. Acta Neuropathol 94: 6-15.

Norambuena A, Wallrabe H, Cao R, et al. 2018. A novel lysosome-tomitochondria signaling pathway disrupted by amyloid- $\beta$ oligomers. $E M B O \mathrm{~J}$ : in press

Norambuena A, Wallrabe H, McMahon L, et al. 2017. mTOR and neuronal cell cycle reentry: how impaired brain insulin signaling promotes Alzheimer's disease. Alzheimers \& Dementia 13: 152-167.

Pilz GA, Bottes S, Betizeau M, et al. 2018. Live imaging of neurogenesis in the adult mouse hippocampus. Science 359: 658662.

Seward ME, Swanson E, Norambuena A, et al. 2013. Amyloid-beta signals through tau to drive ectopic neuronal cell cycle re-entry in Alzheimer's disease. J Cell Sci 126: 1278-1286.
Sorrells SF, Paredes MF, Ebrian-Silla AC, et al. 2018. Human hippocampal neurogenesis drops sharply in children to undetectable levels in adults. Nature 555: 377-381.

Steen E, Terry BM, Rivera EJ, et al. 2005. Impaired insulin and insulin-like growth factor expression and signaling mechanisms in Alzheimer's disease - is this type 3 diabetes? J Alzheimer's Dis 7: $63-80$.

Varvel NH, Bhaskar K, Patil AR, Pimplikar SW, Herrup K, Lamb BT. 2008. Abeta oligomers induce neuronal cell cycle events in Alzheimer's disease. J Neurosci 28: 10786-10793.

Villemagne VL, Burnham S, Bourgeat P, et al. 2013. Amyloid beta deposition, neurodegeneration, and cognitive decline in sporadic Alzheimer's disease: a prospective cohort study. Lancet Neurol 12: $357-367$.

Weingarten MD, Lockwood AH, Hwo S-Y., Kirschner MW. 1975. A protein factor essential for microtubule assembly. Proc Natl Acad Sci U S A 72: 1858-1862.

Yang Y, Mufson EJ, Herrup K. 2003. Neuronal cell death is preceded by cell cycle events at all stages of Alzheimer's disease. $J$ Neurosci 23: 2557-2563.

Zoncu R, Efeyan A, Sabatini DM. 2011. mTOR: from growth signal integration to cancer, diabetes and ageing. Nature Rev Mol Cell Biol 12: 21-35.

Cite this article as: Bloom GS, Norambuena A. 2018. Alzheimer's disease as a metabolic disorder. OCL 25(4): D403. 